\title{
No regulatory double standard for natural health products
}

$\mathrm{M}$ any consumers believe that natural health products are effective therapies and are safer than prescription drugs. This is oddly illogical reasoning. Although both appear to carry a similar Health Canada stamp of approval, there remains a specious dichotomy in the criteria and evidence needed for approval and monitoring of a drug compared with a natural health product.

Before marketing a substance as a drug, a pharmaceutical company must provide extensive evidence, typically from Phase III randomized controlled trials, that its product makes a quantifiable difference in a health condition and that the benefits outweigh the risks. The company must show that it has searched for common serious adverse events. All therapeutic claims are scrutinized, labelling is controlled and manufacturing standards are assured.

The same degrees of scrutiny, control and standardization do not apply to substances classified as natural health products or medicinal foods. This has created a loophole through which manufacturers can sell a product with implied health benefits without having to obtain the supporting scientific evidence that would be needed if it were sold as a drug. Nonmedical participants in the marketing chain seem all too willing to convey misinformation about the ostensible benefits of natural or other nondrug products. Problematic examples from just a single week's recent news headlines include a skin cream claiming to make one slimmer, ${ }^{1}$ a fruit drink supplemented with potentially harmful levels of vitamin $\mathrm{A},{ }^{2}$ and caffeine and herbal extract-infused "energy" drinks, a category whose very name implies an unproven health effect. ${ }^{3}$

The multibillion-dollar natural health products industry sells the perception that because its products are "natural," they must also be safe, such that comprehensive testing like that mandated for pharmaceuticals is not required. However, it is a near-universal truth that any substance that exerts a beneficial effect on a biological system will also have the potential for adverse effects. Therefore, any product truly free of adverse effects is likely to be inert.

Many natural products contain pharmacologically active compounds. Indeed, many of the oldest drugs evolved from herbal remedies to mainstream pharmaceutical products, including salicylates, opiates, curare, vincristine, colchicine, vitamins, quinine and digitalis, as well as more recent examples like artemisinin. Clearly, when a natural health product is truly efficacious, there are no obstacles to scientific validation. Why then should we accept a double standard of proof to allow thousands of such products to make health claims?

A decade ago, Health Canada created the Natural Health Products Directorate, establishing a regulatory framework that was a compromise between foods and drugs. But rather than ensuring safety, efficacy and quality, it has permitted products like the examples described here to be marketed with limited content labelling, poorly documented health benefits and little or no safety data. Consumer confusion has only increased as the number and types of natural health products have burgeoned and the lines between drugs and foods have become even more blurred.

Creating special categories for natural health products or medicinal foods is not the solution. Rather, all health claims for any product should be subject to a common set of regulations, starting with consistent and easily understood standards of evidence proportional to health risks and benefits. Regulatory evaluation should include a review of indications, clear labelling of health claims that an average consumer can understand, assurance of good manufacturing practices and a fulsome statement of product content. Postmarketing surveillance based on levels of potential risk must be in place to ensure that unanticipated adverse risks and serious drug interactions are detected.

Such regulations will add costs for government. However, just as with drugs, natural health products and medicinal foods should be assessed on a cost recovery basis. The high profit margins for many of these products should easily enable manufacturers to pay.

Uniform regulations are the best way to protect consumers while allowing choice. They will also ensure that health professionals have the necessary information about benefits, risks and quality to be able to counsel patients adequately about the health claims advertised for all products sold.

Noni E. MacDonald MD MSc, Stuart MacLeod MD PhD,

Matthew B. Stanbrook MD PhD, Paul C. Hébert MD MHSc;

with editorial advisory team members Ken Flegel MDCM MSc and

Daniel Rosenfield MD

\section{References}

1. Lu V. Nivea rapped a second time. Toronto Star 2011 Sept. 22. Available: www.thestar .com/business/article/1058029-nivea-rapped-a-second-time (accessed 2011 Oct. 14).

2. Schmidt S. Coca-Cola cuts vitamin A content in fruit beverage. Vancouver Sun 2011 Sept. 23. Available: www.vancouversun.com/health/Coca+Cola+cuts+vitamin +content+fruit+beverage/5446524/story.html\#ixzzlalgJY7bE (accessed 2011 Oct. 14).

3. Schmidt S. Energy drinks should only be sold under supervision of a pharmacist: Health Canada panel. National Post 2011 Sept. 20. Available: http://news.nationalpost .com/2011/09/20/energy-drinks-should-only-be-sold-under-supervision-of-a-pharmacist -health-canada-panel (accessed 2011 Oct. 14).

Competing interests: See www.cmaj.ca/site/misc/cmaj_staff.xhtml. Stuart MacLeod is a member of the Pediatric Expert Advisory Committee for Health Canada and has served as an advisor to the World Health Organization Better Medicines for Children Program. None declared for Paul Hébert.

Affiliations: See www.cmaj.ca/site/misc/cmaj_staff.xhtml. Stuart MacLeod is Vice-President, Academic Liaison and Research Coordination, and Professor, Department of Pediatrics, University of British Columbia, Child and Family Research Institute, Vancouver, BC. Paul Hébert is with the Ottawa Health Research Institute, Ottawa, Ont. Daniel Rosenfield is with the Faculty of Medicine, University of Toronto and the Department of Paediatrics, Hospital for Sick Children, Toronto, Ont.

Correspondence to: CMAJ editor, pubs@cmaj.ca

CMAJ 2011. DOI:10.1503/cmaj.111739 